ARTICLE

https://doi.org/10.1038/s41467-019-11351-1

\title{
High performance III-V photoelectrodes for solar water splitting via synergistically tailored structure and stoichiometry
}

\author{
Haneol Lim', James L. Young (10 2 , John F. Geisz (1) ${ }^{2}$, Daniel J. Friedman², Todd G. Deutsch (1) ${ }^{2}$ \& \\ Jongseung Yoon (10) 1,3
}

Catalytic interface of semiconductor photoelectrodes is critical for high-performance photoelectrochemical solar water splitting because of its multiple roles in light absorption, electrocatalysis, and corrosion protection. Nevertheless, simultaneously optimizing each of these processes represents a materials conundrum owing to conflicting requirements of materials attributes at the electrode surface. Here we show an approach that can circumvent these challenges by collaboratively exploiting corrosion-resistant surface stoichiometry and structurally-tailored reactive interface. Nanoporous, density-graded surface of 'black' gallium indium phosphide $\left(\mathrm{GalnP}_{2}\right)$, when combined with ammonium-sulfide-based surface passivation, effectively reduces reflection and surface recombination of photogenerated carriers for high efficiency photocatalysis in the hydrogen evolution half-reaction, but also augments electrochemical durability with lifetime over $124 \mathrm{~h}$ via strongly suppressed kinetics of corrosion. Such synergistic control of stoichiometry and structure at the reactive interface provides a practical pathway to concurrently enhance efficiency and durability of semiconductor photoelectrodes without solely relying on the development of new protective materials.

\footnotetext{
${ }^{1}$ Mork Family Department of Chemical Engineering and Materials Science, University of Southern California, Los Angeles, CA 90089, USA. ${ }^{2}$ National Renewable Energy Laboratory, Golden, CO 80401, USA. ${ }^{3}$ Ming Hsieh Department of Electrical Engineering, University of Southern California, Los Angeles, CA 90089, USA. Correspondence and requests for materials should be addressed to J.Y. (email: jsyoon@alum.mit.edu)
} 
igh-efficiency, high-durability materials for photoelectrochemical (PEC) solar water splitting have been the subject of intense research efforts over the past decades owing to their significant potential to economically produce a pollution-free energy carrier, hydrogen, as well as address the inherent intermittency of solar electricity ${ }^{1-9}$. Among various materials systems considered, a host of superior materials properties including a direct bandgap, appropriate band-edge energetics, as well as ability to monolithically form multiple solid-state junctions with an ideal bandgap combination for absorbing sunlight render III-V compound semiconductors such as gallium arsenide (GaAs) exceptionally attractive for photocatalytic electrodes in solar-driven photoelectrochemical water splitting $4,5,10-12$. Nonetheless, practical utilization of these materials in solar water splitting has been severely hampered largely due to their inherent thermodynamic instability against corrosion in a wide range of $\mathrm{pH}$ under relevant electrochemical potentials of water electrolysis reactions ${ }^{13-16}$. Developing robust protective materials for semiconductor photoelectrodes, however, represents a materials conundrum owing to sophisticated and often conflicting requirements of materials attributes at the reactive interface, where processes in optical absorption, charge transfer, electrocatalysis, as well as protection from corrosion must be simultaneously considered and optimized $^{13,16-19}$.

Gallium indium phosphide $\left(\mathrm{Ga}_{0.51} \mathrm{In}_{0.49} \mathrm{P}\right.$, referred to as $\left.\mathrm{GaInP}_{2}\right)$, a ternary alloy lattice-matched to GaAs, is an indispensable materials component for realizing a ultrahigh $(>20 \%)$ solar-to-hydrogen efficiency due to its near-ideal bandgap energy $(\sim 1.8 \mathrm{eV})$ for the large-bandgap material in multijunction photoelectrodes ${ }^{4,5,12}$. In such tandem systems of solar water splitting, the $\mathrm{GaInP}_{2}$-based top junction is directly exposed to a liquid electrolyte, thereby responsible for not only driving one of the water-splitting half reactions (i.e., hydrogen or oxygen evolution) but also serving as the first optical interface for receiving sunlight. Minimized optical losses and electrochemical durability in corrosive electrolytes are therefore two of the most important materials attributes desired for $\mathrm{GaInP}_{2}$ photoelectrodes. While Fresnel reflection at the semiconductor/ water interface instantly loses a large fraction $(\sim 20-25 \%)$ of incident solar illumination ${ }^{5,11}$, dielectric thin films (e.g., $\mathrm{Si}_{3} \mathrm{~N}_{4}$ ) frequently employed as an antireflective coating (ARC) in photovoltaic devices are not suitable for PEC photoelectrodes because of their inherent instabilities in highly acidic or alkaline electrolytes, poor charge transfer characteristics, and/or the low or lack of catalytic activities in water splitting reactions. In this regard, approaches that can reduce front-surface reflection while enhancing catalytic efficiency and corrosion resistance have been highly sought after as they can realize the full potential of $\mathrm{GaInP}_{2}$ and, in a broader context, III-Vbased photoelectrodes in solar water splitting ${ }^{10,20-23}$. Here, we report a strategy that can address these challenges without solely relying on additionally deposited protective materials. The presented scheme takes advantage of a synergistic combination of density-graded nanoporous materials interface with sulfur-based stoichiometric control to simultaneously achieve enhanced light absorption and catalytic efficiency, as well as suppressed kinetics of corrosion. In the following, systematic studies of optical, morphological, compositional, and electrochemical properties, together with numerical optical modeling based on finite-difference time-domain method, provide quantitative description of underlying scientific principles in the reported system based on $\mathrm{GaInP}_{2}$, a key material that can make an immediate impact to the development of ultrahigh efficiency solar-driven water splitting systems.

\section{Results}

Fabrication of surface-tailored GaInP $_{2}$ photocathodes. As an active material for photocathodes in solar water electrolysis, p-type (Zn-doped, $2 \times 10^{17} \mathrm{~cm}^{-3}$ ) $\mathrm{GaInP}_{2}$ with a thickness of 2.5 $\mu \mathrm{m}$ was grown on a (100) GaAs substrate by an atmospheric pressure metal organic vapor phase epitaxy (MOVPE) ${ }^{5,24}$. Figure 1a schematically illustrates fabrication procedures for surfacetailored $\mathrm{GaInP}_{2}$ photocathodes. The process begins with the oxide-removal of as-grown p-type $\mathrm{GaInP}_{2}$ in dilute $\mathrm{NH}_{4} \mathrm{OH}$ and chromium etchant, followed by dipping into an aqueous solution of silver nitrate $\left(\mathrm{AgNO}_{3}\right)$ and hydrofluoric acid (HF). The silver cations in the solution are electrolessly reduced to form silver nanoparticles that can serve as a hard mask in successive dry etching of $\mathrm{GaInP}_{2}$, where the size and density of silver nanoparticles can be readily controlled by adjusting the concentration of precursors and/or plating time ${ }^{25,26}$. Subsequently, inductively coupled plasma reactive ion etching (ICP RIE) was performed using a gas mixture of $\mathrm{BCl}_{3} / \mathrm{N}_{2}$ to form cone-shaped nanopillars of $\mathrm{GaInP}_{2}$, followed by the removal of residual silver by a wet chemical etchant. After the formation of nanoporous morphology, chemical passivation of nanostructured surface was performed (Supplementary Fig. 1). The surface of 'black' GaInP $\mathrm{P}_{2}$ was soaked in an aqueous solution of ammonium sulfide $\left(\left(\mathrm{NH}_{4}\right)_{2} \mathrm{~S}\right)$, followed by thermal annealing in air to incorporate corrosionresistant surface stoichiometry. In the subsequent discussion, this two-step process consisting of $\left(\mathrm{NH}_{4}\right)_{2} \mathrm{~S}$-passivation and thermal annealing is referred to as $\left(\mathrm{NH}_{4}\right)_{2} \mathrm{~S}$-treatment unless additional specifications are provided. Figure $1 \mathrm{~b}$ shows a tilt-view scanning electron microscope (SEM) image of the representative $\mathrm{GaInP}_{2}$ nanostructure after the dry etching (yet without $\left(\mathrm{NH}_{4}\right)_{2} \mathrm{~S}$-treatment). The diameter of nanopillars gradually decreased from the bottom to the tip, thereby creating a graded index of refraction to suppress front-surface reflection ${ }^{26,27}$. The surface-tailored $\mathrm{GaInP}_{2}$ was then electrically connected with a copper wire on the metal contact at the backside of the sample and encapsulated by thermally cured epoxy to produce fully functional photocathodes ready for driving the hydrogen evolution half-reaction in solar water splitting 28 .

Optical properties of black $\mathrm{GaInP}_{2}$ photocathodes. Efficient coupling of sunlight into the semiconductor photoelectrode is one of the key advantages for the reported black $\mathrm{GaInP}_{2}{ }^{23,26}$. The average heights of $\mathrm{GaInP}_{2}$ nanostructure measured from the cross-sectional SEM images (Fig. 1c) were approximately $\sim 60$, $\sim 320, \sim 450$, and $\sim 550 \mathrm{~nm}$ for etching times of $1,2,3$, and $4 \mathrm{~min}$, respectively. Overall, the height of nanopillars increased with the time of dry etching, while the rate of increase diminished after 2 min under the present experimental conditions. Figure 1d shows the corresponding total (i.e., sum of diffuse and specular) reflectance of nanostructured $\mathrm{GaInP}_{2}$ at near-normal incidence $\left(\theta=8^{\circ}\right)$ in air. The tapered nanopillars strongly suppressed the front-surface reflectance over a broad wavelength range owing to the improved impedance matching arising from a gradually varying refractive index ${ }^{26,29,30}$. The reflectance at $500 \mathrm{~nm}$ decreased from $\sim 33 \%$ for bare $\mathrm{GaInP}_{2}$ to less than $\sim 1 \%$ for nanostructured (3-min-etched) samples (Supplementary Fig. 2). The measured reflectance (solid line) quantitatively matched with the calculated spectra (dotted line) obtained from 3D full-wave numerical optical modeling based on finite-difference timedomain method (FDTD, Lumerical ${ }^{\mathrm{TM}}$ ) (Supplementary Fig. 3 $)^{29,31}$. Using the established numerical model, we also projected the absorption enhancement of nanostructured $\mathrm{GaInP}_{2}$ in the electrolyte (i.e., water) (Fig. 1e). The inset shows integrated solar flux absorption $\left(S_{\text {abs }}\right)$ weighted over a simulated AM1.5 G solar illumination calculated by 
a

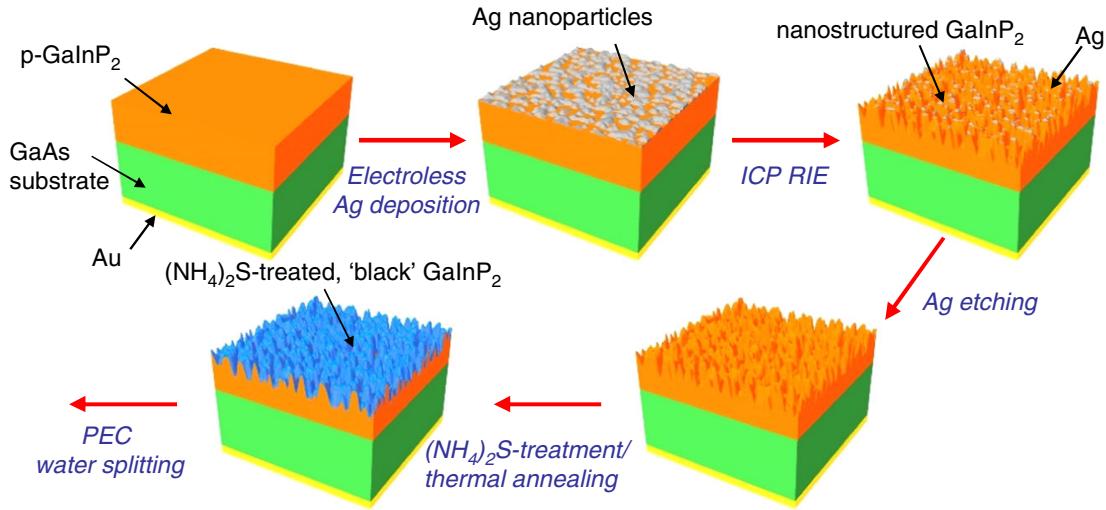

b

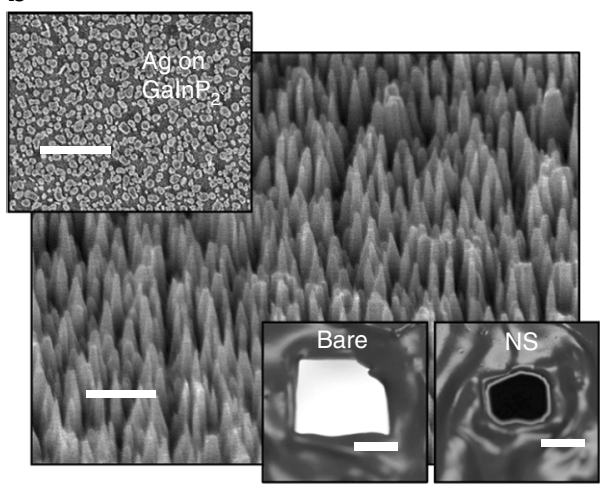

d

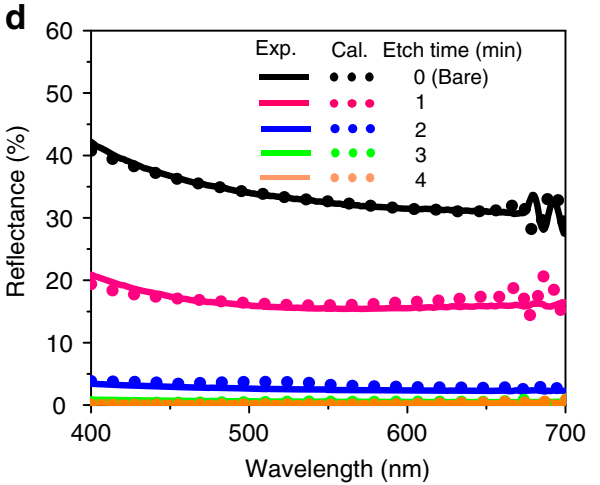

C

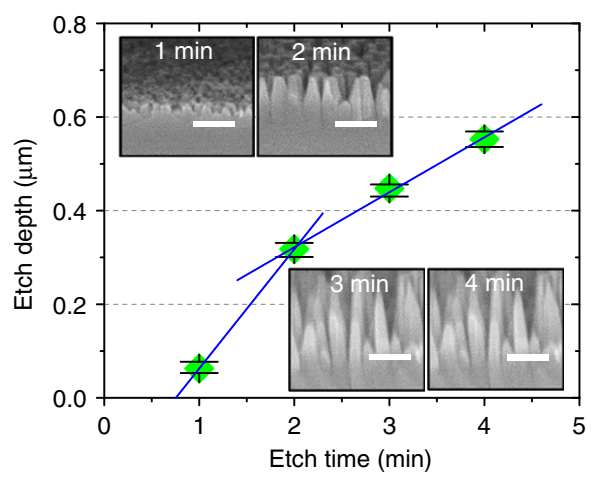

e

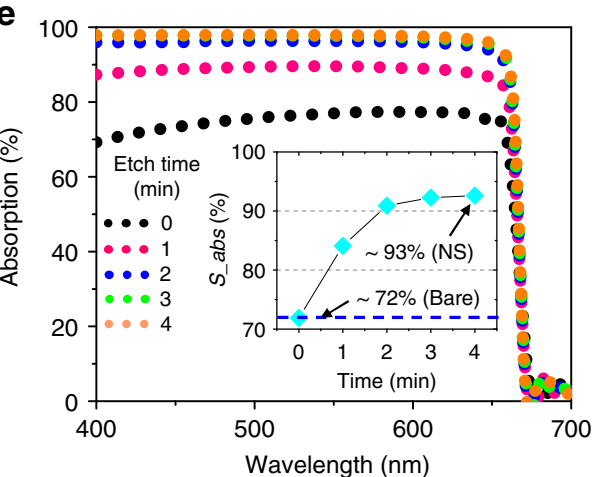

Fig. 1 Schematic illustration, morphological and optical properties of surface-tailored GalnP 2 photocathodes. a Schematic illustration of fabrication procedures for surface-tailored black $\mathrm{GalnP}_{2}$ photocathodes. b Tilt-view scanning electron microscope (SEM) image of nanostructured p-type GalnP 2 photocathodes after the dry etching and before the $\left(\mathrm{NH}_{4}\right)_{2} \mathrm{~S}$-treatment (scale bar: $500 \mathrm{~nm}$ ). The top inset shows a SEM image of electrolessly deposited silver nanoparticles on $\mathrm{GalnP}_{2}$ as a mask for dry etching (scale bar: $1 \mu \mathrm{m}$ ). The bottom inset shows photographic images of fully functional bare (labeled as "Bare") and nanostructured (labeled as "NS") GalnP 2 photocathodes mounted on a slide glass with epoxy encapsulation (scale bar: 5 mm), where the black surface of nanostructured GalnP $\mathrm{P}_{2}$ is evidently shown in contrast to the shiny surface of bare $\mathrm{GalnP}_{2}$. $\mathbf{c}$ Etching depth of the nanostructured GalnP $\mathrm{P}_{2}$ (yet without $\left(\mathrm{NH}_{4}\right)_{2} \mathrm{~S}$-treatment) measured from cross-sectional SEM images (inset) at etching times of 1, 2, 3, and 4 min (scale bar: $300 \mathrm{~nm}$ ). Error bars represent the range of values obtained from three separate measurements $(n=3)$. $\mathbf{d}$ Corresponding total (i.e., specular and diffuse) reflectance spectra of nanostructured GalnP 2 measured on spectrophotometer equipped with an integrating sphere at an incidence angle of $8^{\circ}$. Calculated (dotted line) reflectance spectra obtained from FDTD-based numerical optical modeling matched well with the experimental (solid line) spectra. e Calculated absorption spectra of nanostructured $\mathrm{GalnP}_{2}$ in water using the numerical model established in $\mathbf{d}$. The inset shows corresponding integrated solar flux absorption (S_abs)

where $h, c, A(\lambda)$, and $I_{1.5 \mathrm{G}}(\lambda)$ are Planck's constant, the speed of light, calculated absorption, and the standard solar irradiance (AM 1.5 G; ASTM G-173), respectively ${ }^{11,29}$. The $S_{\text {abs }}$ of black $\mathrm{GaInP}_{2}$ in water is $\sim 92 \%$ (for 3 -min-etched sample), which is considerably higher than the maximum absorption $(\sim 72 \%)$ of bare (i.e., without nanopillars) $\mathrm{GaInP}_{2}$ in water and can be directly translated to the enhanced electrode efficiency. These density-graded morphologies and reflectance spectra of dry- etched $\mathrm{GaInP}_{2}$ were also preserved after the $\left(\mathrm{NH}_{4}\right)_{2} \mathrm{~S}$-treatment (Supplementary Fig. 4).

PEC performance of black GaInP ${ }_{2}$ photocathodes in the HER. The PEC characteristics of black $\mathrm{GaInP}_{2}$ photocathodes in the hydrogen evolution reaction (HER) were studied in a threeelectrode configuration under simulated AM1.5G solar 

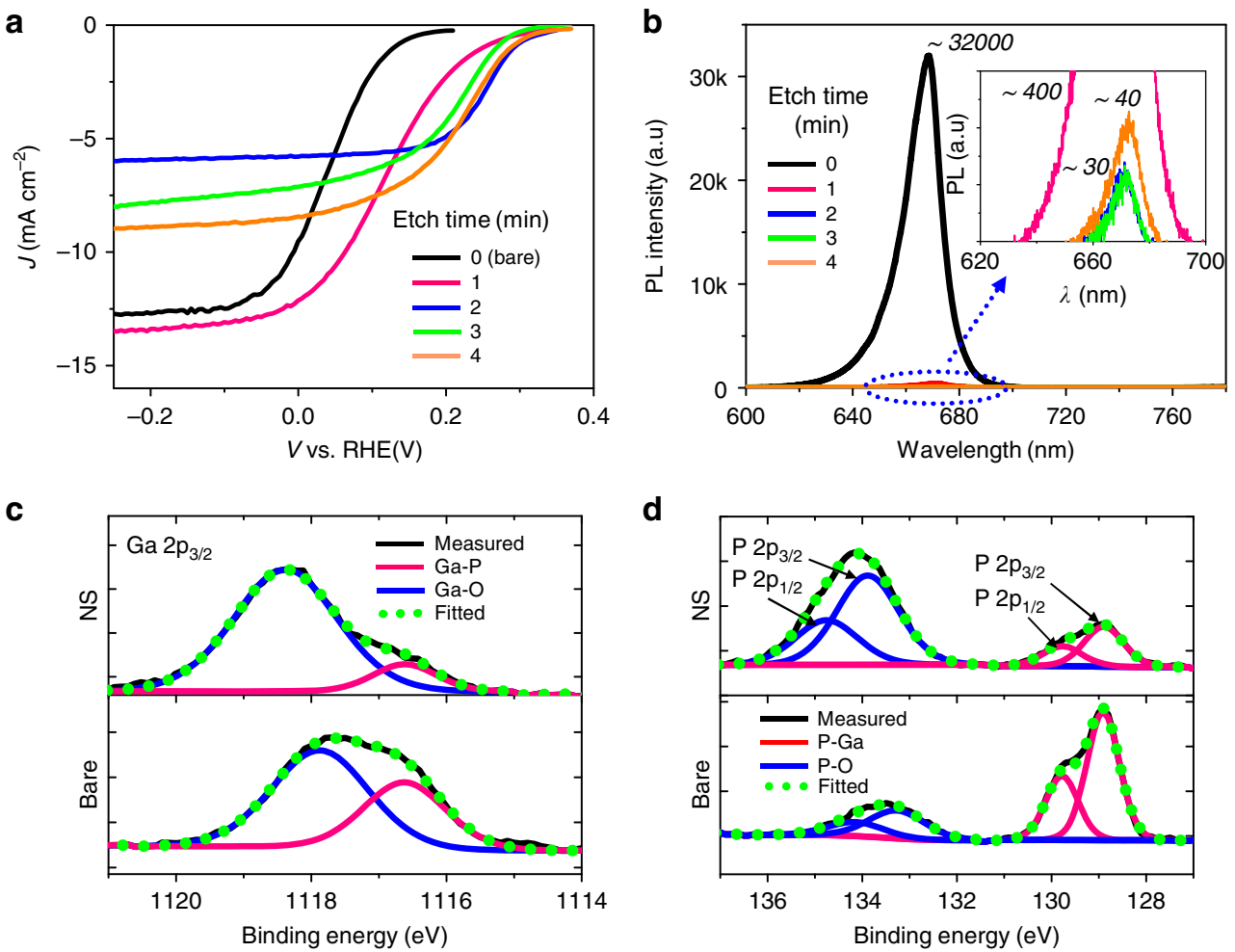

Fig. 2 Photoelectrochemical performance of nanostructured GalnP 2 photocathodes for the HER. a Representative J-E curves of bare and nanostructured Galn $P_{2}$ photocathodes driving the hydrogen evolution reaction (HER), measured under simulated AM1.5 G solar illumination (1000 W/m²). All samples were measured without $\left(\mathrm{NH}_{4}\right)_{2} \mathrm{~S}$-treatment. b Corresponding steady-state photoluminescence $(\mathrm{PL})$ spectra of bare and nanostructured $\mathrm{GalnP}_{2}$ photocathodes. c XPS spectra of $\mathrm{Ga} 2 \mathrm{p}_{3 / 2}$ for bare and nanostructured GalnP2. The measured spectra (black line) matched quantitatively with fitted spectra (green dotted line) composed of deconvoluted Ga-O (blue line) and Ga-P (red line) peaks. $\mathbf{d}$ XPS spectra of $P 2 p_{1 / 2}$ and $2 p_{3 / 2}$ for bare and nanostructured $\mathrm{GalnP}_{2}$. The fitted spectra were deconvoluted to resolve $\mathrm{P}-\mathrm{Ga}$ (red line) and $\mathrm{P}-\mathrm{O}$ (blue line) peaks

illumination $\left(1000 \mathrm{~W} \mathrm{~m}^{-2}\right.$ ), where $\mathrm{Pt}$ and $\mathrm{Ag} / \mathrm{AgCl}$ were used as counter and reference electrodes, respectively, with aqueous sulfuric acid $\left(0.5 \mathrm{M} \mathrm{H}_{2} \mathrm{SO}_{4}\right)$ as an electrolyte (Supplementary Fig. 5) ${ }^{11}$. All samples were measured without $\left(\mathrm{NH}_{4}\right)_{2} \mathrm{~S}$-treatment. Figure 2a shows current density $(J)$-potential $(E)$ curves of the nanostructured $\mathrm{GaInP}_{2}$ photocathodes prepared at various etching times, obtained from a linear sweep voltammetry from -0.5 to $0.4 \mathrm{~V}$ (vs. reversible hydrogen electrode (RHE)), where the data from the first scan were plotted (Supplementary Fig. 6). The efficiency $\left(\eta_{\text {cathode }}\right)$ of $\mathrm{GaInP}_{2}$ photocathodes for the HER was calculated by,

$$
\eta_{\text {cathode }}(\%)=\frac{J_{\max } \cdot\left(E_{\max }-E\left(H^{+} / H_{2}\right)\right)}{P_{\text {in }}} \times 100,
$$

where $J_{\max }$ and $E_{\max }$ are the current density and electrode potential at a maximum power point, $E\left(\mathrm{H}^{+} / \mathrm{H}_{2}\right)$ is the thermodynamic HER potential, and $P_{\text {in }}$ is the power density of simulated AM1.5G solar illumination ${ }^{11,32}$. While this diagnostic efficiency at three-electrode configuration does not fully capture the solarto-hydrogen $(\mathrm{STH})$ efficiency of overall water splitting reactions, it is employed here as a metric to compare the electrode performance quantitatively ${ }^{32}$. As summarized in Supplementary Table 1, the onset potential ( $\left.V_{\text {onset }}\right)$ of all nanostructured $\mathrm{GaInP}_{2}$ photocathodes anodically (i.e., positively along the $x$-axis) shifted compared to the bare $\mathrm{GaInP}_{2}$ because of the reduction of local current density associated with the enlarged surface area and corresponding decrease of over-potential ${ }^{10,23}$. Although a dark current is also increased with the enlarged surface area, the kinetic advantage of a reduced local current density dominates in the trade-off of diminished voltage of a nanostructured surface with a large dark current. Consequently, both fill factor and efficiency greatly improved in nanostructured samples. On the other hand, the saturated current density $\left(J_{\text {sat }}\right)$ slightly increased for 1-min-etched sample compared to the bare $\mathrm{GaInP}_{2}$ owing to the suppressed reflection loss but became smaller at longer etching times. This observation indicates a large degree of surface recombination of photogenerated carriers caused by plasmainduced crystalline defects and oxidation at the nanostructured surface, as supported by the severe attenuation of steady-state photoluminescence (PL) with the dry-etched $\mathrm{GaInP}_{2}$ (Fig. 2b, Supplementary Fig. 7). X-ray photoelectron spectroscopy (XPS) studies also support this analysis. In Fig. $2 c$, the $\mathrm{Ga} 2 \mathrm{p}_{5 / 2}$ peaks with binding energies of 1118.0 and $1116.7 \mathrm{eV}$ observed from bare $\mathrm{GaInP}_{2}$ correspond to $3+$ oxidation states for $\mathrm{Ga}_{2} \mathrm{O}_{3}$ and $\mathrm{GaInP}_{2}$, respectively. Notably, the integrated area of $\mathrm{Ga}-\mathrm{O}$ peak, reflecting the relative amount of $\mathrm{Ga}-\mathrm{O}$ bonding, substantially increased after the dry etching, suggesting the incorporation of oxygen atoms at the etched surface of $\mathrm{GaInP}_{2}$ and generation of defect states within the bandgap that can act as centers for nonradiative carrier recombination ${ }^{33,34}$. With similar origins, the relative amount of $\mathrm{P}-\mathrm{O}$ (In-O) peaks increased over $\mathrm{P}-\mathrm{Ga}$ (In-P) peaks after the formation of nanopillars by dry etching (Fig. 2d, Supplementary Fig. 8).

Effect of $\left(\mathrm{NH}_{4}\right)_{2} \mathrm{~S}$-treatment on PEC performance. To take a full advantage of black $\mathrm{GaInP}_{2}$ in light absorption, it is therefore essential to address the issue of increased carrier recombination associated with etching-induced surface oxidation but also to protect the nanoporous morphology from corrosion. To this end, we soaked the nanostructured $\mathrm{GaInP}_{2}$ in a dilute solution of ammonium sulfide $\left(\left(\mathrm{NH}_{4}\right)_{2} \mathrm{~S}\right)$, followed by thermal annealing in air $\left(250^{\circ} \mathrm{C} \text { for } 1 \mathrm{~h} \text {, Supplementary Fig. } 1\right)^{35,36}$. Figure 3a shows 


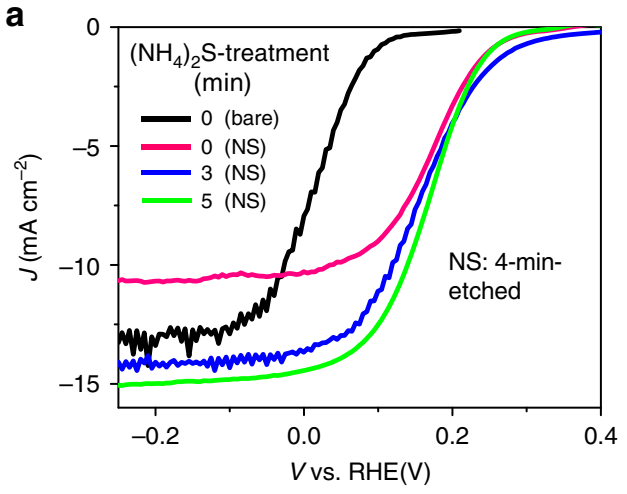

b

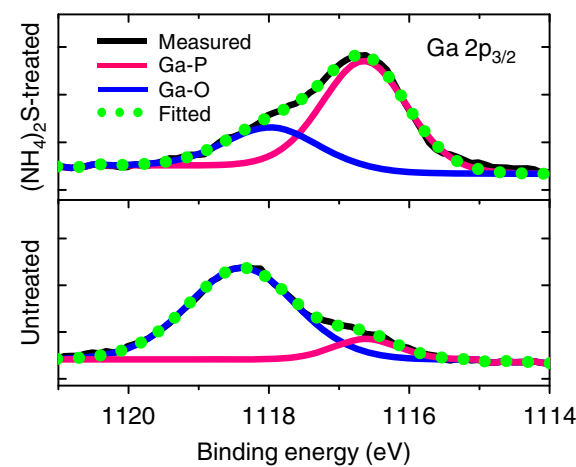

C

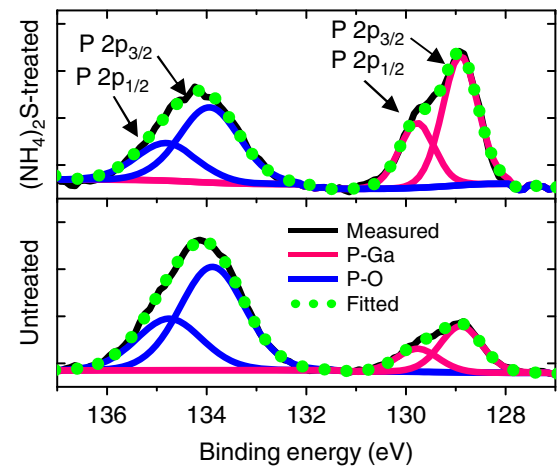

Fig. 3 Photoelectrochemical performance of nanostructured and $\left(\mathrm{NH}_{4}\right)_{2} \mathrm{~S}$ treated Galn $P_{2}$ photocathodes for the HER. a Representative J-E curves of bare and nanostructured $\mathrm{GalnP}_{2}$ photocathodes for the HER after the $\left(\mathrm{NH}_{4}\right)_{2} \mathrm{~S}$-treatment of 3 and 5 min, measured under simulated AM1.5 G solar illumination $\left(1000 \mathrm{~W} / \mathrm{m}^{2}\right)$. XPS spectra of $\mathbf{b}$ Ga $2 \mathrm{p}_{3 / 2}$ and $\mathbf{c} P 2 \mathrm{p}_{1 / 2}$ and $2 \mathrm{P}_{3 / 2}$ for nanostructured $\mathrm{Galn} \mathrm{P}_{2}$ before and after the $\left(\mathrm{NH}_{4}\right)_{2} \mathrm{~S}$ treatment (15 $\mathrm{min})$

$J-E$ curves of 4-min etched $\mathrm{GaInP}_{2}$ photocathodes before and after the $\left(\mathrm{NH}_{4}\right)_{2} \mathrm{~S}$-treatment, plotted with the data for bare $\mathrm{GaInP}_{2}$ as a reference. For samples before the sulfur passivation, the saturated current density $\left(\sim 10.9 \mathrm{~mA} \mathrm{~cm}^{-2}\right)$ of nanostructured $\mathrm{GaInP}_{2}$ was smaller than that $\left(\sim 13.3 \mathrm{~mA} \mathrm{~cm}^{-2}\right)$ of bare $\mathrm{GaInP}_{2}$ owing to the above-described non-radiative carrier recombination. By contrast, the $J_{\text {sat }}$ of the nanostructured $\mathrm{GaInP}_{2}$, after the $\left(\mathrm{NH}_{4}\right)_{2} \mathrm{~S}$-treatment for 3 and $5 \mathrm{~min}$, recovered to $\sim 14.4$ and $\sim 15.2$ $\mathrm{mA} \mathrm{cm}{ }^{-2}$, respectively, resulting in a large improvement of diagnostic efficiency $\left(\eta_{\text {cathode }}\right)$ by over $100 \%$ (relative) compared to the untreated samples (Supplementary Table 2). Such large enhancement of $J_{\text {sat }}$ was also accompanied by the partial recovery of PL intensities (Supplementary Fig. 9), as well as the reduced areas of $\mathrm{Ga}-\mathrm{O}$-related, $\mathrm{P}-\mathrm{O}$-related, and In-O-related peaks in XPS spectra (Fig. 3b, c, Supplementary Fig. 10), suggesting that the substitution of oxygen atoms by sulfur at the surface of nanostructured $\mathrm{GaInP}_{2}$ and corresponding decrease of oxiderelated defect states effectively lowered the extent of surface recombination and thus restored the efficiency of charge transfer at the catalytic interface ${ }^{35,37}$. Along with the $\left(\mathrm{NH}_{4}\right)_{2} \mathrm{~S}$-treatment, the performance of surface-tailored $\mathrm{GaInP}_{2}$ can be further enhanced by additionally depositing materials of high catalytic activity (i.e., co-catalyst) on the electrode surface such as noble metals or molecular catalysts. In the present study, a thin $(\sim 10-30 \mathrm{~nm}$, Supplementary Fig. 11) layer of amorphous molybdenum disulfide $\left(\mathrm{MoS}_{2}\right)$ was photochemically deposited on the nanostructured and $\left(\mathrm{NH}_{4}\right)_{2} \mathrm{~S}$-treated $\mathrm{GaInP}_{2}$ as a HER cocatalyst (Supplementary Figs. 12 and 13). As expected, the $\mathrm{MoS}_{2}$ co-catalyst markedly improved the catalytic performance of surface-tailored $\mathrm{GaInP}_{2}$ in the HER, with a large enhancement in both onset potential and fill factor, resulting in the substantial increase of efficiency by $\sim 20$ times compared to the bare electrode (Supplementary Table 3).

Electrochemical stability of surface-tailored $\mathrm{GaInP}_{2}$. Long-term preservation of intrinsic materials properties and catalytic performance of semiconductor photoelectrodes is one of the most critical requirements for their practical application in solar water splitting. Nevertheless, III-V compound semiconductors including $\mathrm{GaInP}_{2}$ suffer from intrinsic thermodynamic instability and corrode rapidly in a wide range of $\mathrm{pH}$ under the potentials of water splitting reactions, thereby leading to the fast degradation of electrode functionality with an impractically short lifetime $e^{6,14,15,38}$. In this regard, the reported surface-tailoring strategy provides a potential route to strongly enhance the durability of III-V photoelectrodes. Figure $4 \mathrm{a}$, b shows the current density of $\mathrm{GaInP}_{2}$ photocathodes as a function of time for various materials configurations including bare $\mathrm{GaInP}_{2}$ (i.e., with unetched and untreated surface), bare GaInP 2 deposited with $\mathrm{MoS}_{2}$ co-catalyst (yet without $\left(\mathrm{NH}_{4}\right)_{2} \mathrm{~S}$-treatment), nanostructured $\mathrm{GaInP}_{2}$ with $\left(\mathrm{NH}_{4}\right)_{2} \mathrm{~S}$ treatment (yet without $\mathrm{MoS}_{2}$-deposition), and nanostructured $\mathrm{GaInP}_{2}$ with $\mathrm{MoS}_{2}$-deposition (yet without $\left(\mathrm{NH}_{4}\right)_{2} \mathrm{~S}$-treatment), measured at an electrode potential of $0 \mathrm{~V}$ (vs. RHE) in an acidic electrolyte $\left(0.5 \mathrm{M} \mathrm{H}_{2} \mathrm{SO}_{4}\right)$ under simulated AM1.5 G solar illumination. Dry etching and $\left(\mathrm{NH}_{4}\right)_{2} \mathrm{~S}$-treatment were performed for $4 \mathrm{~min}$ and $15 \mathrm{~min}$, respectively. In short-term measurements (i.e., up to $\sim 60 \mathrm{~min}$, Fig. $4 \mathrm{a}$ ), all tested samples exhibited nearly constant current densities except the bare $\mathrm{GaInP}_{2}$, where the rapid degradation of $J$ with bare electrodes (black data) is attributed to the cathodic shift of the $J E$ curve arising from the formation of surface oxide in water, which gradually plateaued due to the self-limiting nature of wet oxidation ${ }^{28}$. The bare electrode deposited with $\mathrm{MoS}_{2}$ (red data) showed comparatively stable performance because of the temporary prevention of surface oxidation by the $\mathrm{MoS}_{2}$ layer. It is noteworthy that the nanostructured $\mathrm{GaInP}_{2}$ after the $\left(\mathrm{NH}_{4}\right)_{2} \mathrm{~S}$ treatment (blue data) remained stable even without the aid of additional protective materials. The extraordinary durability was pronounced more evidently in long-term measurements as depicted in Fig. 4 b. The current density of nanostructured $\mathrm{GaInP}_{2}$ with $\left(\mathrm{NH}_{4}\right)_{2} \mathrm{~S}$-treatment (blue data) was maintained nearly undiminished $(\Delta J<\sim 2 \%)$ for over $\sim 124$ hours, where the measurement was terminated without observing the degradation of electrode performance. It is also notable that the onset potential continuously improved during the stability test (Supplementary Figs. 14-16), which might be attributed to several factors including the activation of catalytic sites of sulfurized $\mathrm{GaInP}_{2}$, as well as enhanced photovoltage and charge transfer efficiency, all occurring with the removal of oxides and/or carbon-containing species that are unstable in the HER (Supplementary Note 1, Supplementary Figs. 17 and 18). By contrast, the bare electrodes 


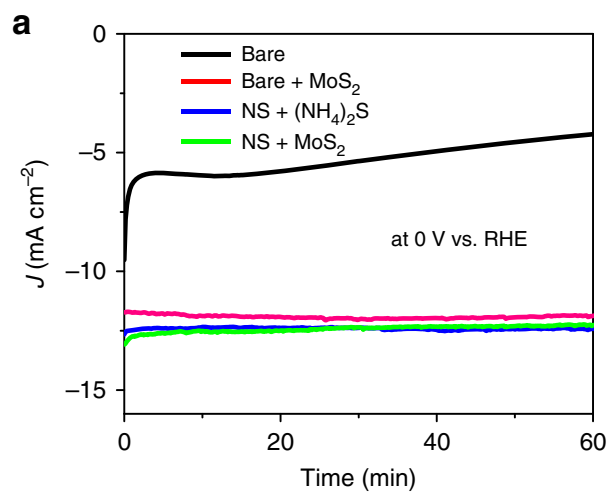

C

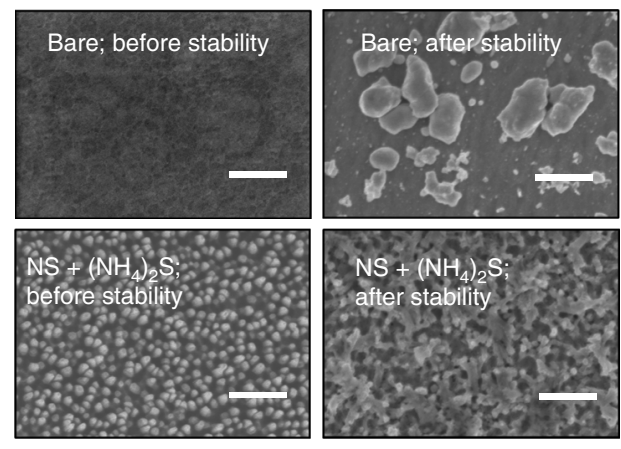

e

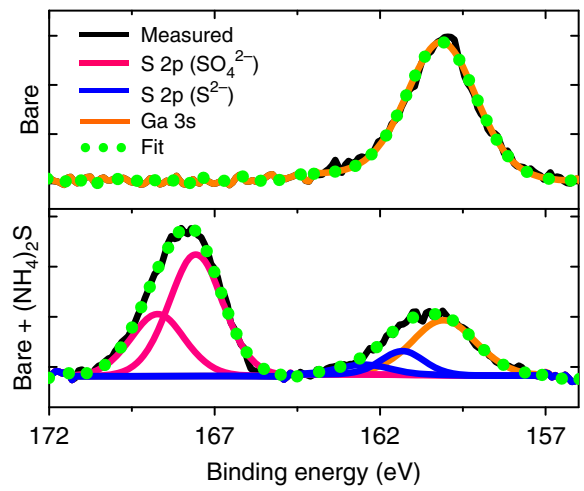

b

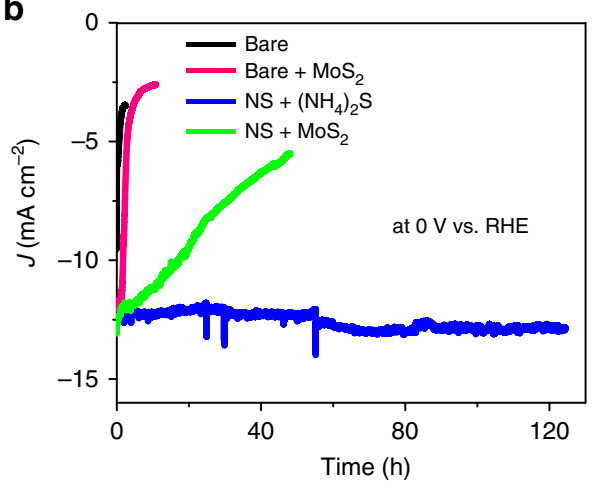

d

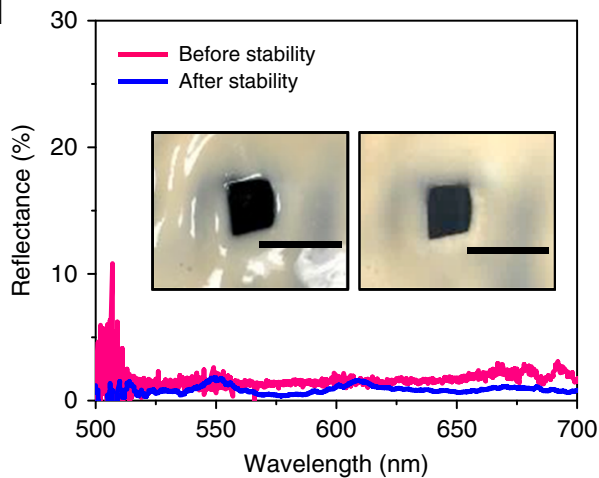

f

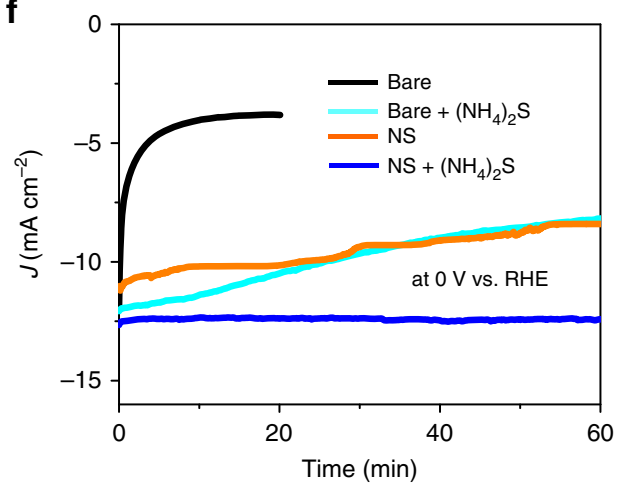

Fig. 4 Electrochemical durability of surface-tailored GalnP 2 photocathodes performing the HER under bias. Current density-time $(J-t)$ plots of GalnP 2 photocathodes in an acidic electrolyte $\left(0.5 \mathrm{M} \mathrm{H}_{2} \mathrm{SO}_{4}\right)$ for $\mathbf{a}$ short-term and $\mathbf{b}$ long-term measurements, at various materials configurations including bare GalnP 2 (black data), bare GalnP 2 deposited with $\mathrm{MoS}_{2}$ (yet without $\left(\mathrm{NH}_{4}\right)_{2} \mathrm{~S}$-treatment, red data), nanostructured GalnP $\mathrm{P}_{2}$ with $\left(\mathrm{NH}_{4}\right)_{2} \mathrm{~S}$-treatment (yet without $\mathrm{MoS}_{2}$-deposition, blue data), and nanostructured $\mathrm{GalnP}_{2}$ with $\mathrm{MoS}_{2}$ (yet without $\left(\mathrm{NH}_{4}\right)_{2} \mathrm{~S}$ treatment, green data), measured at an electrode potential of O V (vs. RHE) under simulated AM1.5 G solar illumination. Dry etching and $\left(\mathrm{NH}_{4}\right)_{2} \mathrm{~S}$-treatment were performed for 4 min and 15 min, respectively. c Top-view SEM images of bare and nanostructured/( $\left(\mathrm{NH}_{4}\right)_{2} \mathrm{~S}$-treated GalnP 2 (scale bar: $500 \mathrm{~nm}$ ) before and after the stability test in b (i.e., $\sim 1 \mathrm{~h}$ for bare, $\sim 124 \mathrm{~h}$ for NS). d Reflectance spectra of nanostructured and $\left(\mathrm{NH}_{4}\right)_{2} \mathrm{~S}$-treated $\mathrm{GalnP}_{2}$ photocathodes before and after the stability test in $\mathbf{b}$. Insets show corresponding photographic images of samples (scale bar: $5 \mathrm{~mm}$ ). e XPS spectra of bare $\mathrm{GalnP}_{2}$ before and after the $\left(\mathrm{NH}_{4}\right)_{2} \mathrm{~S}$-treatment. $\mathbf{f} J$ - $t$ plots of bare and nanostructured $\mathrm{GalnP}_{2}$ photocathodes with and without $\left(\mathrm{NH}_{4}\right)_{2} \mathrm{~S}$-treatment, obtained under the same measurement condition as in a

both with (red data) and without $\mathrm{MoS}_{2}$ (black data) rapidly degraded fast in the early stage $(<3 \mathrm{~h})$ of measurement. In case of the nanostructured $\mathrm{GaInP}_{2}$ with $\mathrm{MoS}_{2}$ but without $\left(\mathrm{NH}_{4}\right)_{2} \mathrm{~S}$ treatment (green data), significant degradation was still noted owing to the delamination or dissolution of $\mathrm{MoS}_{2}$ during the HER. Consistent with these observations, the density-graded surface morphology of nanostructured and $\left(\mathrm{NH}_{4}\right)_{2} \mathrm{~S}$-treated $\mathrm{GaInP}_{2}$ remained nearly intact after the chronoamperometry study (Fig. 4b), as evidenced by the SEM images (Fig. 4c), as well as the preservation of black appearance and low reflectance (Fig. 4d). For bare electrodes, by contrast, significant degrees of corrosion already proceeded just after the $\sim 2.5$-h measurement, where particles with sizes ranging from a few microns to tens of nanometers appeared on the electrode surface as reported in the previous literature ${ }^{39,40}$.

To further elucidate the synergistic contributions of $\left(\mathrm{NH}_{4}\right)_{2} \mathrm{~S}$ treatment and nanoporous surface morphology to the extraordinary improvement of corrosion-resistance, we examined the evolution of surface atomic composition in bare $\mathrm{GaInP}_{2}$ by XPS before and after the $\left(\mathrm{NH}_{4}\right)_{2} \mathrm{~S}$-treatment (Fig. $\left.4 \mathrm{e}\right)$, as well as with and without thermal annealing during the $\left(\mathrm{NH}_{4}\right)_{2} \mathrm{~S}$-treatment (Supplementary Fig. 19). It is noteworthy that the $\left(\mathrm{NH}_{4}\right)_{2} \mathrm{~S}$ treated bare $\mathrm{GaInP}_{2}$ that exhibited stable performance has peaks corresponding to sulfate $\left(\mathrm{SO}_{4}{ }^{2-}\right)$ group (the lower spectra in Fig. 4e), which was introduced during the thermal annealing in the $\left(\mathrm{NH}_{4}\right)_{2} \mathrm{~S}$-treatment ${ }^{8,9}$ (Supplementary Fig. 19). Such sulfate 
$\left(\mathrm{SO}_{4}{ }^{2-}\right)$-related and sulfide $\left(\mathrm{S}^{2-}\right)$-related signals are, however, completely missing in untreated bare $\mathrm{GaInP}_{2}$ (the upper spectra in Fig. 4e) that degraded rapidly. It is therefore concluded that the sulfate group on the sulfurized surface of $\mathrm{GaInP}_{2}$ played a key role in the strongly enhanced durability. On the other hand, the $\left(\mathrm{NH}_{4}\right)_{2} \mathrm{~S}$-treated bare $\mathrm{GaInP}_{2}$ (i.e., without surface nanostructure, cyan data in Fig. $4 \mathrm{f}$ ) did not exhibit a long-term durability comparable to the $\left(\mathrm{NH}_{4}\right)_{2} \mathrm{~S}$-treated and nanostructured $\mathrm{GaInP}_{2}$ (blue data in Fig. $4 \mathrm{f}$ ), while it was still more stable than the untreated bare electrode (black data in Fig. $4 \mathrm{f}$ ), suggesting that the synergistic interplay between the nanostructured morphology to enlarge the surface area and limit the progression of corroded region, and the incorporation of sulfide/sulfate group to confer the improved corrosion resistance is collectively responsible for suppressing the kinetics of corrosion and enabling significantly longer lifetime observed in this study compared to previous works (Supplementary Table 4).

\section{Discussion}

The change of surface morphology observed after the stability test with nanostructured, $\left(\mathrm{NH}_{4}\right)_{2} \mathrm{~S}$-treated $\mathrm{GaInP}_{2}$ might be attributed to the desorption and re-adsorption of $\mathrm{Ga}, \mathrm{In}, \mathrm{P}$, or $\mathrm{S}$ atoms at the catalytic interface, through either faradaic or non-faradaic processes, with the latter independent of corrosion reactions that would be parasitic to the photocurrent. Faradaic efficiencies of $\mathrm{H}_{2}$ measured from bare $\mathrm{GaInP}_{2}$ without and with $\left(\mathrm{NH}_{4}\right)_{2} \mathrm{~S}$-treatment are $\sim 80$ and $\sim 91 \%$ (Supplementary Table 5, Supplementary Fig. 20), respectively, possibly due to the contribution of corrosion to the photocurrent as observed in Fig. 4f. As expected, the faradaic efficiency of $\left(\mathrm{NH}_{4}\right)_{2}$-treated GaInP $\mathrm{P}_{2}$ is higher than the untreated $\mathrm{GaInP}_{2}$ owing to combined effects of surface passivation and suppressed corrosion on the sulfurized reactive interface. Nevertheless, the nanoporous morphology was maintained in ways that produce similar levels of reflectance and light absorption, and thus the photocurrent to those obtained before the stability test. Given that the degradation of $\left(\mathrm{NH}_{4}\right)_{2} \mathrm{~S}$-treated bare $\mathrm{GaInP}_{2}$ has also accompanied the gradual decrease of sulfate group on the electrode surface as evidenced by XPS spectra (Supplementary Fig. 21), we postulate that the rate of electrochemical dissolution of sulfate group is substantially lowered by the nanoporous morphology owing to the reduced rate of local charge transfer associated with the enlarged surface area. While the nanostructured $\mathrm{GaInP}_{2}$ without $\left(\mathrm{NH}_{4}\right)_{2} \mathrm{~S}$-treatment (orange data in Fig.4f) exhibited improved durability compared to the untreated bare electrode, it also steadily degraded at the rate much higher than the nanostructured and $\left(\mathrm{NH}_{4}\right)_{2} \mathrm{~S}$-treated $\mathrm{GaInP}_{2}$, reiterating the importance of collaborative contributions from nanoporous surface morphology and corrosionresistant surface stoichiometry.

In summary, we demonstrated an approach that can simultaneously enhance the light absorption, catalytic efficiency, and durability of $\mathrm{GaInP}_{2}$ photocathodes in the HER of solar water splitting by collaboratively exploiting corrosion-resistant surface stoichiometry and structurally tailored reactive interface. The sulfur treatment has been demonstrated effective for passivating the surface states and suppressing the surface recombination in a wide range of semiconductor materials ${ }^{37,41,42}$. We therefore expect our approach capitalizing the synergistic effect of surface nanostructure and corrosion-resistant surface stoichiometry would be broadly applicable to various semiconductor photoelectrodes (e.g., III-V, III-N) and electrochemical reactions (e.g., oxygen evolution reaction (OER), $\mathrm{CO}_{2}$ reduction) that can benefit from simultaneously enhanced light absorption, catalytic efficiency, and corrosion resistance, all without solely relying on the development of new protective materials, thereby offering practical pathways towards high efficiency, high durability PEC solar water splitting.

\section{Methods}

Fabrication of surface-tailored Galn $\mathbf{P}_{\mathbf{2}}$ photocathodes. A $2.5 \mu \mathrm{m}$-thick p-type $\mathrm{GaInP}_{2}$ (Zn-doped, $2 \times 10^{17} \mathrm{~cm}^{-3}$ ) was epitaxially grown on a GaAs (100) substrate miscut $2^{\circ}$ towards the $(110)$ at $700^{\circ} \mathrm{C}$ by an atmospheric pressure metal organic vapor phase epitaxy (MOVPE). The as-received $\mathrm{GaInP}_{2}$ ep-wafer was cleaned with acetone, isopropyl alcohol (IPA), and deionized (DI) water, followed by the removal of native oxides in a dilute $\mathrm{NH}_{4} \mathrm{OH}$ solution $\left(\mathrm{NH}_{4} \mathrm{OH}(29 \%, \mathrm{EMD})\right.$ : DI water $=1: 10$, by volume, $2 \mathrm{~min}$ ) and perchloric acid solution (CR-7, KMG, 30 s). Silver nanoparticles were electrolessly deposited on $\mathrm{GaInP}_{2}$ in an aqueous solution of silver nitrite $\left(\mathrm{AgNO}_{3}, 10 \mathrm{mM}\right)$ and hydrofluoric acid (HF, $\left.5 \mathrm{M}\right)$.

Nanostructured $\mathrm{GaInP}_{2}$ photocathodes were formed by inductively coupled plasma reactive ion etching (ICP-RIE, STS) $\left(\mathrm{BCl}_{3}: \mathrm{N}_{2}\right.$ (1.5:9 in sccm), $5 \mathrm{mTorr}$, $100 \mathrm{~W} / 500$ $\mathrm{W}, 100^{\circ} \mathrm{C}$ ) using silver nanoparticles as an etch mask. Subsequently, the residual silver was removed by a wet chemical etchant $\left(\mathrm{NH}_{4} \mathrm{OH}: \mathrm{H}_{2} \mathrm{O}_{2}: \mathrm{DI}\right.$ water $=1: 1: 1$, by volume). After the $\left(\mathrm{NH}_{4}\right)_{2} \mathrm{~S}$-treatment and/or $\mathrm{MoS}_{2}$-deposition as described in detail subsequently, a copper wire was connected using a silver paste on the back of the wafer, followed by the encapsulation of side walls using thermally cured epoxy (Loctite $^{\circledast} 9462$ ) to produce fully functional photocathodes.

PEC measurements. All PEC measurements were performed in an aqueous solution (0.5 M, pH: $\sim 0.3-0.35)$ of sulfuric acid $\left(\mathrm{H}_{2} \mathrm{SO}_{4}\right.$, EMD Chemicals, ACS grade, 95-98\%) under simulated AM 1.5 G standard solar illumination $\left(1000 \mathrm{~W} / \mathrm{m}^{2}\right)$ on a full-spectrum solar simulator $(94042 \mathrm{~A}$, Oriel) at ambient temperature $\left(20^{\circ} \mathrm{C}\right)$. The one-sun intensity of solar simulator was calibrated using a certified reference cell $(91150 \mathrm{~V}$, Newport). The electrolyte solution was purged with $\mathrm{N}_{2}$ for $15 \mathrm{~min}$ before each PEC measurement. Linear sweep voltammetry data were collected by a potentiostat (Reference 600, Gamry) under a three-electrode configuration with $\mathrm{Ag} / \mathrm{AgCl}(3 \mathrm{M} \mathrm{NaCl}, \mathrm{RE}-5 \mathrm{~B}$, Bioanalytical Systems) and platinum (MW-1032, Bioanalytical Systems) as reference and counter electrodes, respectively, where the potential of the working electrode was scanned from $-0.8 \mathrm{~V}$ to $0.04 \mathrm{~V}$ vs. $\mathrm{Ag} / \mathrm{AgCl}\left(-0.57 \mathrm{~V}\right.$ to $0.27 \mathrm{~V}$ vs. RHE) for bare $\mathrm{GaInP}_{2}$, from $-0.8 \mathrm{~V}$ to $0.14 \mathrm{~V}$ vs. $\mathrm{Ag} / \mathrm{AgCl}(-0.57$ to $\sim 0.37 \mathrm{~V}$ vs. $\mathrm{RHE})$ for nanostructured $\mathrm{GaInP}_{2}$, and from $-0.8 \mathrm{~V}$ to $\sim 0.4 \mathrm{~V}$ vs. $\mathrm{Ag} / \mathrm{AgCl}\left(-0.57 \mathrm{~V}\right.$ to $\sim 0.63 \mathrm{~V}$ vs. RHE) for $\mathrm{MoS}_{2}$ deposited $\mathrm{GaInP}_{2}$, respectively, at a scan rate of $20 \mathrm{mV} / \mathrm{s}$ in a step size of $5 \mathrm{mV}$. Note that the potential sweep was done from negative to positive potential to avoid overestimation of electrode performance (Supplementary Fig. 5). A small amount of surfactant (Triton X-100, SPI Supplies) was added to the electrolyte to facilitate the release of generated hydrogen bubbles from the electrode surface. For the conversion of electrode potential from $\mathrm{Ag} / \mathrm{AgCl}$ to the reversible hydrogen electrode (RHE), a linear sweep voltammetry scan was performed using a platinum electrode (MF-2013, Bioanalytical Systems) as a cathode to experimentally determine the onset potential of hydrogen evolution. The current density $(J)$ was evaluated based on the measured area of illuminated electrode surface (Supplementary Note 2). For Figs. 2a, 3a, 4a, b, f, representative data from two or three batches of experiments were reported.

$\left(\mathbf{N H}_{\mathbf{4}} \mathbf{~}_{\mathbf{2}} \mathbf{S}\right.$-treatment. To tailor the surface atomic composition of $\mathrm{GaInP}_{2}$, a preheated $\left(\mathrm{NH}_{4}\right)_{2} \mathrm{~S}$ solution $\left(\sim 61^{\circ} \mathrm{C}, \sim 0.77 \mathrm{M}\right.$, prepared by adding $34 \mathrm{~mL}$ of DI water or isopropanol to $10 \mathrm{~mL}$ of as-received $\left(\mathrm{NH}_{4}\right)_{2} \mathrm{~S}$ solution (Macron, $20.0-24.0 \mathrm{wt} \%$ in $\left.\mathrm{H}_{2} \mathrm{O}\right)$ ) was cast onto the surface of bare or nanostructured $\mathrm{GaInP}_{2}$ placed on a hot plate $\left(\sim 85^{\circ} \mathrm{C}\right)$ for $3-5 \mathrm{~min}$ (for samples in Fig. 3a). The treatment time for samples in Fig. 3b, c, and 4 was 15 min. Subsequently, samples were dried under $\mathrm{N}_{2}$, followed by thermal annealing at $250^{\circ} \mathrm{C}$ in air for $1 \mathrm{~h}$.

$\mathbf{M o S}_{\mathbf{2}}$-deposition. For $\mathrm{MoS}_{2}$-deposition, the $\mathrm{GaInP}_{2}$ was immersed in an aqueous solution of $\left(\mathrm{NH}_{4}\right)_{2} \mathrm{MoS}_{4}\left(1 \mathrm{mM}\right.$, Sigma Aldrich) and $0.5 \mathrm{M}$ of $\mathrm{Na}_{2} \mathrm{SO}_{4}$ buffer $(\mathrm{pH}$ 6.6) under white light (LED-6WD, AmScope) illumination $\left(\sim 20 \mathrm{~mW} / \mathrm{cm}^{2}\right)$ for $5 \mathrm{~min}$ at an open-circuit condition, followed by rinsing with DI water and drying under $\mathrm{N}_{2}$. After the photochemical deposition, the sample was thermally annealed at $250{ }^{\circ} \mathrm{C}$ under $\mathrm{N}_{2}$ atmosphere for $1 \mathrm{~h}$. Alternatively, $\mathrm{MoS}_{2}$ was also electrochemically deposited by scanning 8-10 times of potential cycles between -0.4 and $+0.15 \mathrm{~V}$ vs. $\mathrm{Ag} / \mathrm{AgCl}$ (i.e., one cycle: $-0.4 \mathrm{~V} \rightarrow+0.15 \mathrm{~V} \rightarrow-0.4 \mathrm{~V}$ ) using the same regents as in photochemical deposition under a dark condition.

Reflectance measurement. Reflectance spectra of $\mathrm{GaInP}_{2}$ photocathodes (Fig. 1d) were recorded using UV-Vis-NIR spectroscopy (Lamda 950, Perkin-Elmer) at near-normal incidence $\left(\theta=8^{\circ}\right)$ in air, measured on a spectrophotometer equipped with an integrating sphere using a Spectralon ${ }^{\otimes}$ as a $100 \%$ reflectance standard. For the data in Fig. $4 \mathrm{~d}$, reflectance spectra were recorded using a home-made optical set-up consisting of a white light source (HL-2000, Ocean Optics) and a fiber-optic spectrometer (Flame-T-VIS-NIR, Ocean Optics). The source light was collimated by an achromatic doublet lens $(f=19 \mathrm{~mm}, \mathrm{~N} . \mathrm{A} .=0.42)$ and then focused on the cell region (beam diameter $=\sim 50 \mu \mathrm{m})$ through an objective lens $(\times 20, \mathrm{~N} . \mathrm{A} .=0.4)$ The reflected light was collected by the same objective lens and guided to the 
spectrometer through a multimode fiber. A silver mirror deposited on fused silica (PF10-03-P01, Thorlabs) was used as a $100 \%$ calibration standard.

Photoluminescence measurement. Photoluminescence (PL) spectra of bare and nanostructured $\mathrm{GaInP}_{2}$ samples were measured using a Raman microscope $\left(\mathrm{XploRA}^{\mathrm{TM}}\right.$, HORIBA Jobin Yvon Inc.) with $\times 100$ objective lens (NA: 0.90), where a 532-nm laser was focused on the sample surface with a beam diameter of $\sim 1 \mu \mathrm{m}$.

X-ray photoelectron spectroscopy (XPS). XPS was performed on a Kratos Axis Ultra DLD, where photoelectrons were generated by monochromatic $\mathrm{Al} \mathrm{Ka} \mathrm{X-ray}$ at $1486.7 \mathrm{eV}$ at a base pressure of $4 \times 10^{-8}$ torr. Binding energies were calibrated by $\mathrm{C} 1 \mathrm{~s}$ peak at $284.8 \mathrm{eV}$. Linear-least-squares fitting of XPS spectra was performed using CasaXPS software (Casa Software Ltd.) using convolution of Gaussian (70\%) and Lorentzian $(30 \%)$ line-shapes. The peak positions and relative intensity ratios are nearly identical between bare and nanostructured samples under the present experimental conditions (Supplementary Fig. 22).

Atomic force microscopy (AFM) and ellipsometry. The thickness of $\mathrm{MoS}_{2}$ was measured by tapping-mode atomic force microscope (AFM, Dimensional 3100, Digital Instrument). Refractive index $(n)$ and extinction coefficient $(k)$ of $\mathrm{GaInP}_{2}$ were measured by spectroscopic ellipsometry (VASE ${ }^{\circledR}$ Ellipsometer, J.A.Woollam).

Numerical optical modeling. Reflectance and absorption spectra of nanostructured $\mathrm{GaInP}_{2}$ photocathodes were numerically modeled by finite-difference time-domain method (FDTD). To produce a model nanostructured surface, topview SEM micrographs $\left(\sim 1.2 \times 0.9 \mu \mathrm{m}^{2}\right)$ of the dry-etched $\mathrm{GaInP}_{2}$ at various etching times were imported to a 3D modeling software (Rhinoceros ${ }^{\circledR}$ ), where lateral profiles of nanopillars were adjusted to closely match with those observed experimentally. The created nanostructured surface was further imported to the FDTD software (FDTD Solutions, Lumerical ${ }^{\mathrm{TM}}$ ). For calculation at normal incidence, a 3D simulation volume was confined with periodic boundary conditions for the $x$-direction and $y$-direction, and a perfectly matched layers (PML) boundary condition for the $z$-direction, where a continuous plane wave that has a broad Gaussian frequency spectrum $(270-750 \mathrm{THz}$ or $400-1100 \mathrm{~nm})$ was assumed as a light source.

Faradaic efficiency measurement. Hydrogen and oxygen gases were collected volumetrically by a Hoffman-type apparatus from bare $\mathrm{GaInP}_{2}$ photocathodes with and without $\left(\mathrm{NH}_{4}\right)_{2} \mathrm{~S}$-treatment. The photocathodes were operated at $0 \mathrm{~V}$ vs. RHE using $\mathrm{Pt}$ and $\mathrm{Hg} / \mathrm{Hg}_{2} \mathrm{SO}_{4}$ (MSE) as counter and reference electrodes, respectively, in $0.5 \mathrm{M}$ sulfuric acid illuminated by a tungsten-halogen lamp with water filter calibrated to one Sun intensity using a $\mathrm{GaInP}_{2}$ reference cell. Faradaic efficiency was calculated with the following equation:

$$
\begin{aligned}
& \eta_{\mathrm{H}_{2}}=\frac{\text { Collected gas quantity }(\mathrm{mol})}{\text { Expected gas quantity }(\mathrm{mol})} \\
& \left({ }^{P_{H_{2}} \mathrm{~V}}\right.
\end{aligned}
$$

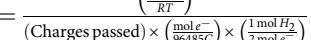

where $P_{H_{2}}$ is the pressure of the evolved hydrogen gas, $V$ is the volume, $R$ is the gas constant $\left(62363 \mathrm{~mL} \cdot\right.$ torr $\left.\cdot \mathrm{K}^{-1} \cdot \mathrm{mol}^{-1}\right)$ and $T$ is temperature $(292.59 \mathrm{~K})$. More detailed procedures of faradaic efficiency measurements appear elsewhere ${ }^{5}$.

Reporting summary. Further information on research design is available in the Nature Research Reporting Summary linked to this article.

\section{Data availability}

The data that support the plots within this paper and other findings of this study are available from the corresponding authors upon reasonable request.

Received: 6 November 2018 Accepted: 3 April 2019

Published online: 29 July 2019

\section{References}

1. Yang, Y. et al. Semiconductor interfacial carrier dynamics via photoinduced electric fields. Science 350, 1061-1065 (2015).

2. Fujishima, A. \& Honda, K. Electrochemical photolysis of water at a semiconductor electrode. Nature 238, 37-38 (1972).

3. Kenney, M. J. et al. High-performance silicon photoanodes passivated with ultrathin nickel films for water oxidation. Science 342, 836-840 (2013).

4. Khaselev, O. \& Turner, J. A. A monolithic photovoltaic-photoelectrochemical device for hydrogen production via water splitting. Science 280, 425-427 (1998).
5. Young, J. L. et al. Direct solar-to-hydrogen conversion via inverted metamorphic multi-junction semiconductor architectures. Nat. Energy 2 , 17028 (2017).

6. $\mathrm{Hu}$, S. et al. Amorphous $\mathrm{TiO} 2$ coatings stabilize $\mathrm{Si}, \mathrm{GaAs}$, and $\mathrm{GaP}$ photoanodes for efficient water oxidation. Science 344, 1005-1009 (2014).

7. Lin, $\mathrm{Y}$. et al. Role of $\mathrm{TiO} 2$ surface passivation on improving the performance of p-InP photocathodes. J. Phys. Chem. C. 119, 2308-2313 (2015).

8. Gu, J. et al. A graded catalytic-protective layer for an efficient and stable water-splitting photocathode. Nat. Energy 2, 16192 (2017).

9. King, L. A., Hellstern, T. R., Park, J., Sinclair, R. \& Jaramillo, T. F. Highly stable molybdenum disulfide protected silicon photocathodes for photoelectrochemical water splitting. ACS Appl. Mater. Interfaces 9, 36792-36798 (2017)

10. Lee, M. H. et al. p-Type InP nanopillar photocathodes for efficient solardriven hydrogen production. Angew. Chem. 124, 10918-10922 (2012).

11. Kang, D. et al. Printed assemblies of GaAs photoelectrodes with decoupled optical and reactive interfaces for unassisted solar water splitting. Nat. Energy 2, 17043 (2017)

12. Gu, J. et al. Water reduction by a p-GaInP2 photoelectrode stabilized by an amorphous $\mathrm{TiO} 2$ coating and a molecular cobalt catalyst. Nat. Mater. 15, 456-460 (2016).

13. Britto, R. J. et al. Molybdenum disulfide as a protection layer and catalyst for gallium indium phosphide solar water splitting photocathodes. J. Phys. Chem. Lett. 7, 2044-2049 (2016).

14. Pourbaix, M. Atlas of Electrochemical Equilibria in Aqueous Solutions. (National Association of Corrosion Engineers, 1974).

15. Park, S.-M. \& Barber, M. E. Thermodynamic stabilities of semiconductor electrodes. J. Electroanal. Chem. Interfacial Electrochem. 99, 67-75 (1979).

16. Walter, M. G. et al. Solar water splitting cells. Chem. Rev. 110, 6446-6473 (2010).

17. Turner, J. et al. Renewable hydrogen production. Int. J. Energy Res 32, 379-407 (2008).

18. Montoya, J. H. et al. Materials for solar fuels and chemicals. Nat. Mater. 16, 70-81 (2017).

19. Chen, X. B., Shen, S. H., Guo, L. J. \& Mao, S. S. Semiconductor-based photocatalytic hydrogen generation. Chem. Rev. 110, 6503-6570 (2010).

20. Park, J. H., Kim, S. \& Bard, A. J. Novel carbon-doped $\mathrm{TiO} 2$ nanotube arrays with high aspect ratios for efficient solar water splitting. Nano Lett. 6, 24-28 (2006).

21. Wang, H., Deutsch, T. \& Turner, J. A. Direct water splitting under visible light with nanostructured hematite and WO3 photoanodes and a GaInP2 photocathode. J. Electrochem. Soc. 155, F91-F96 (2008).

22. Tilley, S. D., Cornuz, M., Sivula, K. \& Grätzel, M. Light-induced water splitting with hematite: improved nanostructure and iridium oxide catalysis. Angew. Chem. 122, 6549-6552 (2010)

23. Oh, J., Deutsch, T. G., Yuan, H.-C. \& Branz, H. M. Nanoporous black silicon photocathode for $\mathrm{H} 2$ production by photoelectrochemical water splitting. Energy Environ. Sci. 4, 1690-1694 (2011).

24. Essig, S. et al. Raising the one-sun conversion efficiency of III-V/Si solar cells to $32.8 \%$ for two junctions and $35.9 \%$ for three junctions. Nat. Energy 2,17144 (2017).

25. Sayed, S. Y., Daly, B. \& Buriak, J. M. Characterization of the interface of gold and silver nanostructures on InP and GaAs synthesized via galvanic displacement. J. Phys. Chem. C. 112, 12291-12298 (2008).

26. Chan, L. et al. Broadband antireflection and absorption enhancement of ultrathin silicon solar microcells enabled with density-graded surface nanostructures. Appl. Phys. Lett. 104, 223905 (2014).

27. Huang, Y.-F. et al. Improved broadband and quasi-omnidirectional antireflection properties with biomimetic silicon nanostructures. Nat. Nanotechnol. 2, 770 (2007).

28. Shen, L. et al. Nanostructured silicon photocathodes for solar water splitting patterned by the self-assembly of lamellar block copolymers. ACS Appl. Mater. Interfaces 7, 26043-26049 (2015).

29. Lee, S. M. et al. High performance ultrathin gaas solar cells enabled with heterogeneously integrated dielectric periodic nanostructures. ACS Nano $\mathbf{9}$, 10356-10365 (2015)

30. Lee, S. M. et al. Printable nanostructured silicon solar cells for highperformance, large-area flexible photovoltaics. ACS Nano 8, 10507-10516 (2014).

31. Lee, S. M. et al. High-performance flexible nanostructured silicon solar modules with plasmonically engineered upconversion medium. Adv. Energy Mater. 5, 1500761 (2015)

32. Chen, Z. et al. Accelerating materials development for photoelectrochemical hydrogen production: Standards for methods, definitions, and reporting protocols. J. Mater. Res. 25, 3-16 (2011).

33. Dean, P. J., Henry, C. H. \& Frosch, C. J. Infrared donor-acceptor pair spectra involving the deep oxygen donor in gallium phosphide. Phys. Rev. 168, 812-816 (1968) 
34. Schubert, E. F. Doping in III-V Semiconductors. (Cambridge University Press, 1993).

35. Tsai, C.-D. \& Lee, C.-T. Passivation mechanism analysis of sulfur-passivated InGaP surfaces using x-ray photoelectron spectroscopy. J. Appl. Phys. 87, 4230-4233 (2000).

36. Tajik, N., Haapamaki, C. M. \& LaPierre, R. R. Photoluminescence model of sulfur passivated p-InP nanowires. Nanotechnology 23, 315703 (2012).

37. Bessolov, V. N. \& Lebedev, M. V. Chalcogenide passivation of III-V semiconductor surfaces. Semiconductors 32, 1141-1156 (1998).

38. Young, J. L., Steirer, K. X., Dzara, M. J., Turner, J. A. \& Deutsch, T. G. Remarkable stability of unmodified GaAs photocathodes during hydrogen evolution in acidic electrolyte. J. Mater. Chem. A 4, 2831-2836 (2016).

39. Wang, H. \& Turner, J. Stability of GaInP2 in H2SO4 solution for photoelectrochemical water splitting. ECS Trans. 2, 125-133 (2007).

40. Wang, H., Deutsch, T., Welch, A. \& Turner, J. A. The stability of illuminated p-GaInP2 semiconductor photoelectrode. Int. J. Hydrog. Energy 37, 14009-14014 (2012).

41. Lee, C.-T., Lan, M.-H. \& Tsai, C.-D. Improved performances of InGaP Schottky contact with $\mathrm{Ti} / \mathrm{Pt} / \mathrm{Au}$ metals and MSM photodetectors by (NH4)2Sx treatment. Solid-State Electron. 41, 1715-1719 (1997).

42. Varadhan, P. et al. Surface passivation of GaN nanowires for enhanced photoelectrochemical water-splitting. Nano Lett. 17, 1520-1528 (2017).

\section{Acknowledgements}

J.Y. and H.L. gratefully acknowledge support from National Science Foundation (ECCS1509897, CBET-1707169). The authors thank the Center for Energy Nanoscience at USC for the use of spectrophotometer, the USC Center of Excellence for Molecular Characterization for the use of spectrophotometers, Donghai Zhu and John Curulli for help using facilities at Keck photonics laboratory and center for electron microscope and microanalysis (CEMMA) at USC, respectively. The authors also thank Jun Liu and AlJassim Mowafak for help in focused ion beam (FIB) and scanning tunneling electron microscopy (STEM) and Fanqi Wu for help with atomic force microscopy (AFM). J.L.Y., J.F.G., D.J.F., and T.G.D. acknowledge support by the U.S. Department of Energy (DOE), Office of Energy Efficiency and Renewable Energy, Fuel Cell Technologies Office and Solar Energy Technology Office under Contract No. DE-AC36-08GO28308 with the National Renewable Energy Laboratory. The U.S. government retains and the publisher, by accepting the article for publication, acknowledges that the U.S. government retains a nonexclusive, paid-up, irrevocable, worldwide license to publish or reproduce the published form of this work, or allow others to do so, for U.S. government purposes. The views and opinions of the authors expressed herein do not necessarily state or reflect those of the United States Government or any agency thereof. Neither the United States
Government nor any agency thereof, nor any of their employees, makes any warranty, expressed or implied, or assumes any legal liability or responsibility for the accuracy, completeness, or usefulness of any information, apparatus, product, or process disclosed, or represents that its use would not infringe privately owned rights.

\section{Author contributions}

J.Y. and H.L. conceived the idea and designed the experiment. H.L., J.L.Y., J.F.G., D.J.F., T.G.D. and J.Y. performed the experiments. H.L., J.L.Y., J.F.G., D.J.F., T.G.D. and J.Y. analyzed the data. H.L., J.L.Y., J.F.G., T.G.D. and J.Y. wrote the paper.

\section{Additional information}

Supplementary Information accompanies this paper at https://doi.org/10.1038/s41467 019-11351-1.

Competing interests: The authors declare no competing interests.

Reprints and permission information is available online at http://npg.nature.com/ reprintsandpermissions/

Peer review information: Nature Communications thanks the anonymous reviewer(s) for their contribution to the peer review of this work.

Publisher's note: Springer Nature remains neutral with regard to jurisdictional claims in published maps and institutional affiliations.

(c) (i) Open Access This article is licensed under a Creative Commons Attribution 4.0 International License, which permits use, sharing, adaptation, distribution and reproduction in any medium or format, as long as you give appropriate credit to the original author(s) and the source, provide a link to the Creative Commons license, and indicate if changes were made. The images or other third party material in this article are included in the article's Creative Commons license, unless indicated otherwise in a credit line to the material. If material is not included in the article's Creative Commons license and your intended use is not permitted by statutory regulation or exceeds the permitted use, you will need to obtain permission directly from the copyright holder. To view a copy of this license, visit http://creativecommons.org/ licenses/by/4.0/.

(C) The Author(s) 2019 